\title{
Closed-Loop Recycling of Copper from Waste Printed Circuit Boards Using Bioleaching and Electrowinning Processes
}

\author{
Mahsa Baniasadi 1,2,5 John E. Graves ${ }^{1,3} \cdot$ Daniel A. Ray ${ }^{1,2,5} \cdot$ Angélique Lindamulage De Silva $^{4} \cdot$ Derek Renshaw $^{1,2}$. \\ Sebastien Farnaud ${ }^{1,2}$ (1)
}

Received: 28 February 2020 / Accepted: 13 June 2020 / Published online: 29 June 2020

(c) The Author(s) 2020

\begin{abstract}
In the present study, a model of closed-loop recycling of copper from PCBs is demonstrated, which involves the sequential application of bioleaching and electrowinning to selectively extract copper. This approach is proposed as part of the solution to resolve the challenging ever-increasing accumulation of electronic waste, e-waste, in the environment. This work is targeting copper, the most abundant metal in e-waste that represents up to $20 \%$ by weight of printed circuit boards (PCBs). In the first stage, bioleaching was tested for different pulp densities $(0.25-1.00 \% \mathrm{w} / \mathrm{v})$ and successfully used to extract multiple metals from PCBs using the acidophilic bacterium, Acidithiobacillus ferrooxidans. In the second stage, the method focused on the recovery of copper from the bioleachate by electrowinning. Metallic copper foils were formed, and the results demonstrated that $75.8 \%$ of copper available in PCBs had been recovered as a high quality copper foil, with $99+\%$ purity, as determined by energy dispersive X-ray analysis and Inductively-Coupled Plasma Optical Emission Spectrometry. This model of copper extraction, combining bioleaching and electrowinning, demonstrates a closed-loop method of recycling that illustrates the application of bioleaching in the circular economy. The copper foils have the potential to be reused, to form new, high value copper clad laminate for the production of complex printed circuit boards for the electronics manufacturing industry.
\end{abstract}

\section{Graphic Abstract}

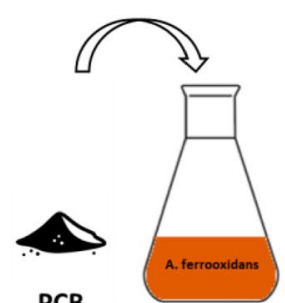

PCB
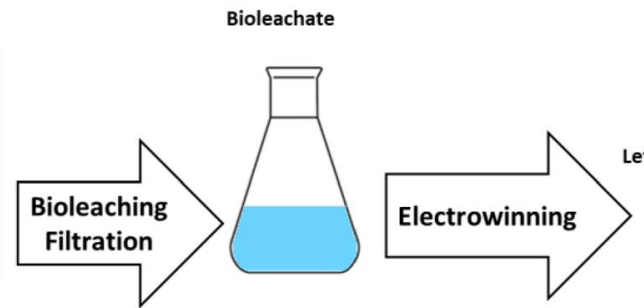

Left over solution

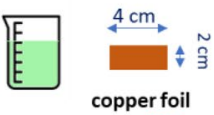

copper foil

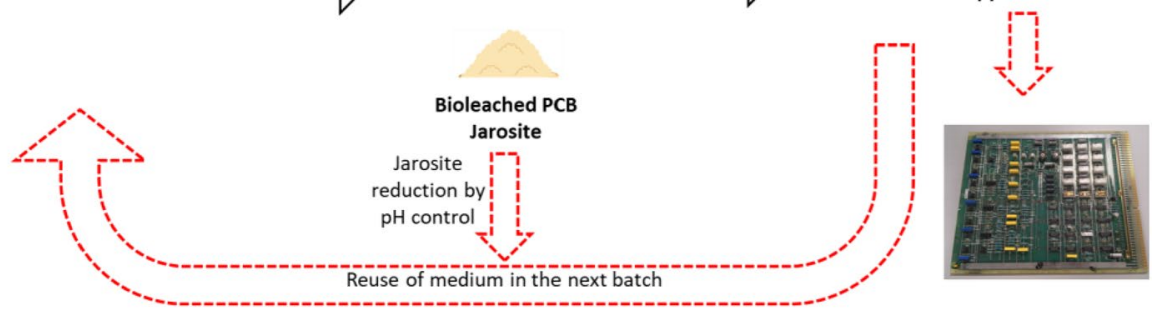

----- Potential of material reuse and recycle

Keywords Bioleaching $\cdot$ Copper recovery $\cdot$ Electrowinning $\cdot$ Printed circuit boards $\cdot$ Recycling $\cdot$ WEEE

Sebastien Farnaud

sebastien.farnaud@coventry.ac.uk

Extended author information available on the last page of the article 


\section{Statement of Novelty}

The use and value of copper are high and so there are both environmental and economic drivers for recovering copper efficiently. Redundant Printed Circuit Boards (PCBs) constitute a rich source of copper. The focus of this work is the demonstration of 'closed-loop' recycling of copper from PCBs via bioleaching and electrowinning processes. Typically, ion exchang or solvent extraction techniques are required to concentrate and purify the dissolved copper before electrowinning. These processes add expense and in the latter case use toxic, low flash point solvents. This work confirms the recovery of a pure copper product, in good yield, by electrowinning directly from bioleachate. The new process is shorter, more cost-efficient and an environmentally friendly means of recycling the valuable metal.

\section{Introduction}

Every year, $72 \%$ of copper extracted from natural resources, with high cost and energy consumption, is used for the production of electrical and electronic equipment [1]. In addition to the depletion of natural resources, metal recovery from primary resources has a high carbon footprint, with an estimated $127 \mathrm{Mt} \mathrm{CO}_{2 \mathrm{eq}}$ of greenhouse gas globally [2]. Due to consumer demand and rapid technological innovation, electrical and electronic equipment has a short life span. Within a few years, discarded equipment including the bulk of the metal content is predominantly sent to landfill, which demonstrates an environmentally unsustainable approach that is commonly practiced in the IT industry [3]. To address these issues, urban mining is being developed to promote a circular economy and the reuse of metals in electrical and electronic equipment. This new trend has transformed waste electrical and electronic equipment (WEEE) into a secondary source of metals [4]. Methods traditionally used for metal extraction from ores in the mining industry, including pyrometallurgy, hydrometallurgy but also bioleaching, can be used to extract metals from secondary resources.

Several commercialized plants worldwide are available for recycling of e-waste by either hydrometallurgy or pyrometallurgy. For instance, Dowa Eco-System published the use of advanced metallurgical methods to recycle up to 22 metal elements [5]. Similarly, Boliden Rönnskär, claims to produce $201 \mathrm{kt}$ copper, $33 \mathrm{kt}$ zinc clinker, $26 \mathrm{kt}$ lead, 384 tons silver and 12 tons gold in 2019 from recycling of e-waste [6]. In addition to scrap products from the electrical and electronic engineering industries, metal recovery plants are also essential to process other solid wastes including emission control catalyst, rechargeable batteries, bottom ash/fly ash and heavy metal-containing sludge [7]. Despite technology readiness, pyrometallurgy and hydrometallurgy, which are still widely used in industry, remain very challenging for the environment. Pyrometallurgy is highly energy-intensive as it requires smelting at $300-900{ }^{\circ} \mathrm{C}$ and, when applied to WEEE, it may cause the emission of toxic gases, such as furan and dioxin due to the presence of brominated flame retardants $[8,9]$. Similarly, by using toxic chemical solutions, which include sulphuric acid, nitric acid, hydrochloric acid and hydrogen peroxides, hydrometallurgy techniques expose natural water resources to the risk of acidification and pollution, for which sophisticated wastewater treatment techniques are required [10]. A comparative study between bioleaching and hydrometallurgy processes, regarding their environmental impact for copper and zinc recovery from PCBs [9] confirmed that of all recycling methods applied to metal treatment, bioleaching, which uses bacteria to recover metals from a solid matrix, remains the most sustainable method for metal recovery from WEEE; bioleaching has $0.4 \mathrm{~kg} \mathrm{CO}_{2 \mathrm{eq}}$ whereas hydrometallurgy had $0.7 \mathrm{~kg} \mathrm{CO}_{2 \text { eq }}$ carbon footprint [8]. In addition to its environmental benefits, bioleaching requires less investment than conventional metal recovery methods [8]. It should also be noted that the most widely used bacteria in bioleaching are acidophilic bacteria that have been isolated from the natural environment [11].

An important component in almost all electrical and electronic equipment is the printed circuit board (PCB). In this study, PCBs originating from IT networking and telecommunication equipment, which to our knowledge have not been investigated as a source of electronic waste for bioleaching and electrowinning, are investigated for copper recycling. Networking and telecommunication facilities contain switchboards that are rich sources of critical metals, which provide environmental and economic incentives for recovery. In particular, boards from outdated technology contain higher levels of precious metals. PCBs are generally manufactured from polymers, metals and ceramics, with a very heterogeneous metallic fraction containing over 20 different elements including noble, base and rare earth metals [12]. Whereas the polymer content of PCBs can be used for the production of liquid and gas fuel through thermochemical methods such as gasification and pyrolysis $[13,14]$, the most abundant metal in all types of PCBs is copper, which is commonly used due to its high conductivity and relatively low cost [1].

Bioleaching converts metals attached and buried in the laminar PCB from their elemental state into solubilised metallic ions [8]. Acidithiobacillus ferrooxidans, which is the most commonly used bacterial species for bioleaching, 
has been proven successful for metal recovery from several e-waste sources, including lithium ion batteries $[15,16]$, Ni-Cd batteries [17], computer PCBs [18], mobile phone PCBs [19] and light emitting diode (LED) lamps [20]. The effects of different pulp densities of e-waste (LED lamps) on metabolic activity and adaptation of $A$. ferrooxidans, have been described elsewhere, and concluded that the maximum pulp density of LED lamp that A. ferrooxidans can tolerate is $1.5 \% \mathrm{w} / \mathrm{v}$ [21].

To recover the metal in its final pure elemental state for reuse in a new product, several methods have been proposed including cementation, sulphide precipitation, ion exchange and electrowinning [22-24]. Electrowinning process is the method expected to provide the highest purity of final product in a form of copper foil [25]. However, the heterogeneous metal content of PCBs is challenging for electrowinning, as the bioleachate mixture resulting from the leached waste contains several other base metals and components in addition to copper. The novelty of this work is combining both technologies, the electrowinning process with bioleaching. Selective electrowinning of copper that can deliver a valuable, high purity product from such a complex mixture of metals and metabolites, is a challenge, particularly with the significant amount of iron that is required as the electron donor in the bioleaching process for acidophiles [26].

Electrowinning was combined with leaching of electronic waste in other research works [27-29], but although bioleaching has been investigated as a sustainable method for metal solubilisation from PCBs, to our knowledge, applying electrowinning directly to the bioleachate has not been considered before. Recently, a cementation method for metal recovery from e-waste was tested and copper with $93 \%$ purity was obtained, but the product was in the form of copper precipitates [25]. For metal recovery from the solution obtained from bioleaching of PCBs, solvent extraction has been applied [30], a process that is followed by electrowinning. The purity of the recovered copper was reported to be 99.83\% pure. In the present work, electrowinning of copper directly from bioleachate is reported for the first time. This process avoids the need for solvent extraction, reduces operational costs and eliminates the use of toxic, low flash point solvents [31].

\section{Materials and Method}

\section{PCB Characterisation}

The PCBs used in this work were obtained from switch boards of IT networking and telecommunication equipment, which were manufactured by Alcatel in 2001. The PCBs were shredded using an industrial shredder. Although the optimal particle size for bioleaching has been reported to be 100 microns [32], such small size particles have been avoided in this work, in order to adopt the most sustainable process that would reduce energy consumption, dust formation and loss of valuable metals.

Metal content of the ashed PCB sample was determined as follows: samples were first ashed at $550{ }^{\circ} \mathrm{C}$ for $12 \mathrm{~h}$ in a furnace (Lenton, ECF) to remove volatile fractions; then digested in aqua regia at $70{ }^{\circ} \mathrm{C}$ on a hot plate for $24 \mathrm{~h}$. Following filtration, the resulting solution was analysed by Inductively-Coupled Plasma Optical Emission Spectrometry (ICP-OES) using a Perkin Elmer Optima 8300 and calibrated using standard solutions obtained from Merck (TraceCERT®). This calibration was carried out using diluted standard solutions using a five point standard range $(10-100 \mathrm{mg} / \mathrm{l})$. The correlation coefficient for copper was 0.9997 .

\section{Bioleaching Method}

The acidophilic bacterium used in this study was A. ferrooxidans, from the Acidophile Laboratory Bangor University, Wales, UK. A. ferrooxidans is chemolithoautotroph sulphur and iron-oxidising bacterium, which is able to convert ferrous iron to ferric, so that in turn ferric ions oxidise the base metals available in PCBs and solubilise them in their ionic form. Bacteria were grown in $9 \mathrm{k}$ medium containing: $\left(\mathrm{NH}_{4}\right)_{2} \mathrm{SO}_{4} 3.0(\mathrm{~g} / \mathrm{l}), \mathrm{KCl} 0.1(\mathrm{~g} / \mathrm{l}), \mathrm{K}_{2} \mathrm{HPO}_{4} 0.5(\mathrm{~g} / \mathrm{l})$, $\mathrm{MgSO}_{4} \cdot 7 \mathrm{H}_{2} \mathrm{O} 0.5(\mathrm{~g} / \mathrm{l}), \mathrm{Ca}\left(\mathrm{NO}_{3}\right)_{2} 0.01(\mathrm{~g} / \mathrm{l}), \mathrm{FeSO}_{4} \cdot 7 \mathrm{H}_{2} \mathrm{O}$ $44.2(\mathrm{~g} / \mathrm{l})$, in distilled water, with $\mathrm{pH}$ adjusted to 2.0 , using sulphuric acid $(1.0 \mathrm{M})$. Each $250 \mathrm{ml}$ Erlenmeyer flask contained $100 \mathrm{ml}$ of medium. The bacteria were grown in a shaker-incubator at $30{ }^{\circ} \mathrm{C}$ and agitated at $50 \mathrm{rpm}$. The adopted method was a two-step bioleaching process, where the electronic waste was added after the growth phase of the bacteria. The growth curve of $A$. ferrooxidans has been characterised elsewhere [21,33] by cell counting. In the first 2 to 4 days following inoculation, the bacterial population increased exponentially during the log phase; in two-step bioleaching, the addition of e-waste is carried out following the log phase at the start of stationary phase, which is considered as full bacterial growth. In the current study, before the addition of e-waste, the concentration of ferric ions increased from 0 at time of inoculation, to a maximum of $7.8 \mathrm{~g} / \mathrm{l}$ after 2 days. Similarly, after 2 days of growth, the oxidation reduction potential (ORP) had climbed from an initial $310 \mathrm{mV}$ at inoculation to $510 \mathrm{mV}$. Both increased parameters indicated full bacterial growth.

Once full growth had been reached, sterilised shredded PCBs were added to the flasks at a pulp density within the range of $0.25-1.00 \% \mathrm{w} / \mathrm{v}$. The rotation speed was increased to $160 \mathrm{rpm}$ for the bioleaching process. Daily sampling was performed to monitor the change in $\mathrm{pH}$ of the solution, the ORP of the medium, the concentration of ferric ions and 
metal content by ICP-OES analysis. A Thermo Scientific $\mathrm{pH}$ meter was used to monitor $\mathrm{pH}$ and a Thermo Scientific Sure-Flow Combi Redox/ORP electrode filled with $\mathrm{Ag} / \mathrm{AgCl}$ solution was used for the Redox measurements. It was calibrated daily using Thermo Scientific ORP standard 900,011. Ferric ion concentration was determined by spectrophotometry using the 5-sulfosalicylic acid method. This method relies on the reaction of 5-sulfosalicylic acid with ferric ions available in the medium, which translates into a violet color, intensity of which is measured with a spectrophotometer at $500 \mathrm{~nm}$. The color intensity can be translated into a concentration, using a calibration curve obtained from dissolution of $\mathrm{Fe}_{2}\left(\mathrm{SO}_{4}\right)_{3}$ at defined concentrations in distilled water [34]. The nature and concentration of metals in the solution were determined at the end of bioleaching process, after filtration with Whatman filter paper Grade 541, using the ICP-OES method mentioned in Sect. 2.1. These values were further used to determine the metal recovery efficiency.

\section{Electrowinning}

To determine the optimum conditions for electrowinning, mimic solutions with metal concentrations similar to the bioleachate were used. The concentration of all metals in the bioleachate were determined by ICP-OES; the mimic solution in the first step, was prepared using sulphate salts of each metal in equivalent amount. In the next set, a $9 \mathrm{k}$ medium solution was prepared that contained all the components mentioned in Sect. 2.2. However, the amount of iron was defined according to the ICP-OES results. The electrowinning tests were performed in a cell containing an anode and a cathode. The cathode was a 316 stainless steel sheet (length: $9 \mathrm{~cm}$, width: $2 \mathrm{~cm}$ and $0.1 \mathrm{~cm}$ thickness) and the anode was an insoluble titanium mesh coated in a mixed metal oxide $\left(\mathrm{IrO}_{2}-\mathrm{Ta}_{2} \mathrm{O}_{5}\right)$. The leachate was stirred at $500 \mathrm{rpm}$ using a magnet stirrer to facilitate the transport of metal ions to the cathode surface. A fairly high stirring rate was chosen to avoid mass transport limitations from convection processes. The reverse side of the stainless steel plate was covered with plating tape (RS components) to prevent copper deposition. The area of the cathode immersed in solution was calculated as 8 $\mathrm{cm}^{2}$. The plating time for actual bioleachate was set at $3 \mathrm{~h}$, a value obtained as optimal time in this work, after investigating the effect of electrowinning time on plating efficiency and quality of the product. The current density was set at $10 \mathrm{~mA} / \mathrm{cm}^{2}$. Assuming $100 \%$ efficiency, the mass of copper deposited under these conditions is theoretically $0.28 \mathrm{~g}$ after $3 \mathrm{~h}$. It is expected that this mass of copper should form a $40 \mu \mathrm{m}$ thick foil for this electrode area. The actual mass of the plated copper was calculated by measuring the weight of the cathode before and after electrowinning. From these values the current efficiency and the percentage of copper recovery of the electrowinning process was calculated. As the $\mathrm{pH}$ of the bioleachate was 2.0 , the $\mathrm{pH}$ of mimic solutions was also adjusted to pH 2.0 using $1 \mathrm{M}$ sulphuric acid.

\section{Product Characterisation}

The obtained foils were analysed using a Carl Zeiss, 1530 VP field emission gun scanning electron microscope (FEGSEM) and energy dispersive X-ray (EDX) analysis for morphology and purity respectively. The accelerating voltage used for secondary electron imaging and EDX was $20 \mathrm{kV}$. The surface morphology was examined on the final product after electrodeposition and foil removal. Energy dispersive X-ray (EDX) analysis was carried out using an Oxford Instruments X-Max $80 \mathrm{~mm}^{2}$ EDX detector. The thickness of the copper was also measured by viewing prepared foils on the SEM. The purity of the foil was also confirmed using ICP-OES analysis, after digestion of foil with aqua regia.

\section{Results and Discussion}

\section{PCB Content}

The metal content, which was determined by ICP-OES, was calculated to contain $36.11 \mathrm{wt} \%$ base metals, 0.01 $\mathrm{wt} \%$ rare earth metals and $0.02 \mathrm{wt} \%$ precious metals. The detailed metal concentration of the PCB (Table 1) showed that the most abundant metal was copper, which represents $29.04 \mathrm{wt} \%$ of the e-waste. This value is in the mid-range of the copper content as reported by other researchers [12]. In addition to base metals, noble metals were also identified. For example, gold, which is used widely in PCBs for its stability (excellent corrosion resistance, good wear resistance when alloyed with other metals) and high conductivity, was found to be present in significant quantities. Furthermore, other metals such as gallium, present in gallium nitride $(\mathrm{GaN})$ transistors as semi-conductive materials [35], as well as the rare earth element neodymium, found in magnetic actuators, were identified [36].

Table 1 PCB metal content (mg/g PCB)

\begin{tabular}{llllll}
\hline $\mathrm{Cu}$ & $\mathrm{Cr}$ & $\mathrm{Ga}$ & $\mathrm{Fe}$ & $\mathrm{Pb}$ & $\mathrm{Mn}$ \\
290.37 & 0.02 & 0.05 & 8.23 & 17.84 & 2.27 \\
$\mathrm{Mg}$ & $\mathrm{Ni}$ & $\mathrm{Al}$ & $\mathrm{Ag}$ & $\mathrm{Zn}$ & \\
1.20 & 3.52 & 33.89 & 0.08 & 3.67 & \\
$\mathrm{Au}$ & $\mathrm{Pd}$ & $\mathrm{Pt}$ & $\mathrm{Nd}$ & & \\
0.17 & 0.05 & 0.01 & 0.11 & & \\
\hline
\end{tabular}




\section{Bioleaching Results}

Heavy metals and organic materials, such as epoxy polymer and brominated flame retardants available in PCBs, have some toxic effects for the growth and activity of bacteria [37]. The toxicity of organic and inorganic anions, except sulphate, is more challenging for acidophilic bacteria than transition metal cations [38]. This can present a limitation to the amount of PCBs that can be processed in each batch. The effects of pulp density on growth and activity of bacteria is shown in Fig. 1.

When ferrous ions act as electron donor for bacteria, electrons travel across the bacterial membrane, against the redox potential gradient in an uphill pathway. This process requires energy, which is obtained from the influx of protons into the bacteria via the proton gradient that is created by the acidic $\mathrm{pH}$ of the medium. These protons are also suggested to be involved in the reduction of oxygen to water, again relying on the proton gradient caused by the difference in internal and external $\mathrm{pH}$ [39].

In the presence of A.ferrooxidans, two reactions are taking place in the medium, where Eq. 1 is the biological reaction and Eq. 2 is the chemical hydrolysis of ferric ions [17]:

$$
\begin{aligned}
& 2 \mathrm{Fe}^{2+}+\frac{1}{2} \mathrm{O}_{2}+2 \mathrm{H}^{+} \rightarrow 2 \mathrm{Fe}^{3+}+\mathrm{H}_{2} \mathrm{O} \\
& \mathrm{Fe}^{3+}+\mathrm{nH}_{2} \mathrm{O} \rightarrow \mathrm{Fe}(\mathrm{OH})_{\mathrm{n}}^{(3-\mathrm{n})+}+\mathrm{nH}^{+}
\end{aligned}
$$
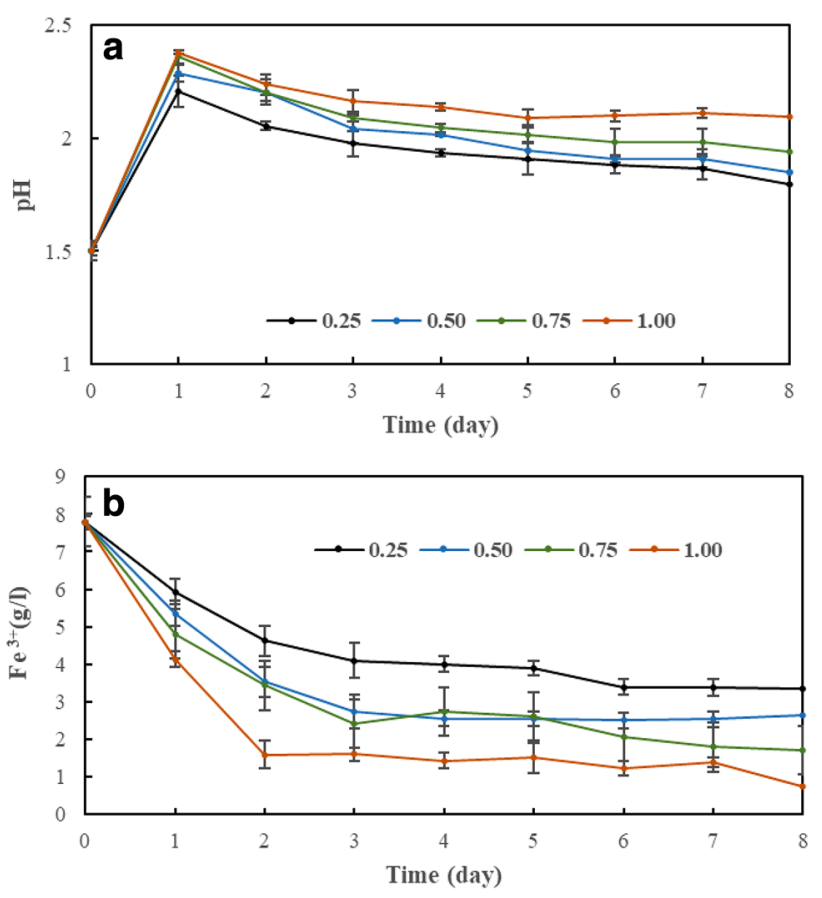

Fig. 1 a $\mathrm{pH}$, b ferric ion concentration versus bioleaching time as an indication of bacterial growth and activity for different pulp densities
Following the addition of metal-containing e-waste $\left(\mathrm{M}^{0}\right)$ (Eq. 3), an initial pH increase was observed, which is proposed to be the result of: (1) the alkali reaction due to the cleavage of amine curing agents from in epoxy resin [37], and (2) a decreased proton production by Eq. 2 due to the consumption of ferric ions as described in the redoxolysis reactions (Eq. 3).

$\mathrm{M}^{0}+2 \mathrm{Fe}^{3+} \rightarrow \mathrm{M}^{2+}+2 \mathrm{Fe}^{2+}$

During the bioleaching process, epoxy goes through depolymerization through proton consumption. The epoxy content of e-waste is depolymerized after cleavage of bisphenol monomers, a very weak organic acid, and amine curing reagents [37]. As shown in Fig. 1a, the higher the pulp density, the sharper the $\mathrm{pH}$ increase, as more PCB is released into the medium. Reciprocally, at the later stage, a decrease in $\mathrm{pH}$ can be observed: as the remaining metal content in the solid waste decreases, less ferric ions are consumed, as described in Eq. 3 and more ferric ions remain available for Eq. 2, so the proton production increases as by reaction mentioned in Eq. 2. In addition, the rate of Eq. 1 also decreases as the bacteria reaches its death phase.

The same trends were reported for the bioleaching of button-cell batteries in another research work [40]. Finally, the $\mathrm{pH}$ stabilises and becomes constant after three days of bioleaching. The role of the bacteria can be seen as the continuous generation of metabolites that can act as leaching agents [41]. Lower ferric ion concentration in the medium, with higher amount of PCBs, is due to the lower rate of regeneration cycle (biological conversion of ferrous to ferric ions with Eq. 1) during bioleaching, due to the toxicity of PCBs and their inhibitory effect and more consumption of ferric ions in Eq. 3 as more metals are available in the medium. The decrease in the amount of ferric ions (Fig. 1b) was due to the formation of jarosite at higher concentration of ferric ion and higher $\mathrm{pH}$. This reaction took place at a $\mathrm{pH}$ greater than 2 , and by reaction of ferric hydroxides with monovalent cations including $\mathrm{K}^{+}$and $\mathrm{NH}_{4}{ }^{+}$, available in the $9 \mathrm{k}$ medium [42]. Since A. ferrooxidans is both an iron and sulphur oxidizing bacteria, it can be expected that a lower jarosite formation would lead to a higher bioleaching rate, and would facilitate the consumption of ferrous sulphate in the process as will be discussed later in Sect. 3.5.

Analysis of variance (ANOVA) with $\alpha=0.05$ of the obtained results (Table 2) Indicates a significant effect of pulp density on both parameters ( $\mathrm{pH}$ and ferric ion concentration) indicated by very low F-values. Figure 2 illustrates change of ORP with time. No significant effect of pulp density on ORP was observed. In a two-step bioleaching procedure, electronic waste is added when the ORP is high as it is the beginning of stationary phase when the maximal amount of ferric ions is available in the solution. It was suggested 
Table 2 Analysis of variance (ANOVA) for $\mathrm{pH}$, and ferric concentration

\begin{tabular}{|c|c|c|c|c|c|c|}
\hline Source of Variation & SS & $\mathrm{df}$ & MS & $\mathrm{F}$ & $\mathrm{P}$-value & F crit \\
\hline \multicolumn{7}{|l|}{ ANOVA for $\mathrm{pH}$} \\
\hline Pulp density & 0.568 & 3 & 0.189 & 40.478 & 0.000 & 2.748 \\
\hline Time & 1.398 & 7 & 0.200 & 42.685 & 0.000 & 2.156 \\
\hline Interaction & 0.059 & 21 & 0.003 & 0.600 & 0.903 & 1.723 \\
\hline Within & 0.299 & 64 & 0.005 & & & \\
\hline Total & 2.325 & 95 & & & & \\
\hline \multicolumn{7}{|c|}{$\begin{array}{l}\text { ANOVA for ferric con- } \\
\text { centration }\end{array}$} \\
\hline Pulp density & 68.787 & 3 & 22.929 & 96.121 & 0.000 & 2.748 \\
\hline Time & 77.424 & 7 & 11.061 & 46.367 & 0.000 & 2.156 \\
\hline Interaction & 6.961 & 21 & 0.331 & 1.390 & 0.158 & 1.723 \\
\hline Within & 15.267 & 64 & 0.239 & & & \\
\hline Total & 168.439 & 95 & & & & \\
\hline
\end{tabular}

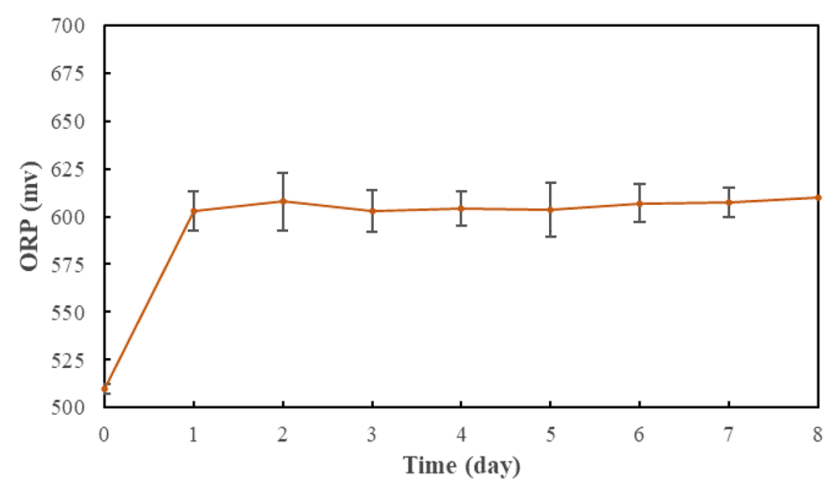

Fig. 2 ORP vs. bioleaching time (pulp density $1 \% \mathrm{w} / \mathrm{v}$ )

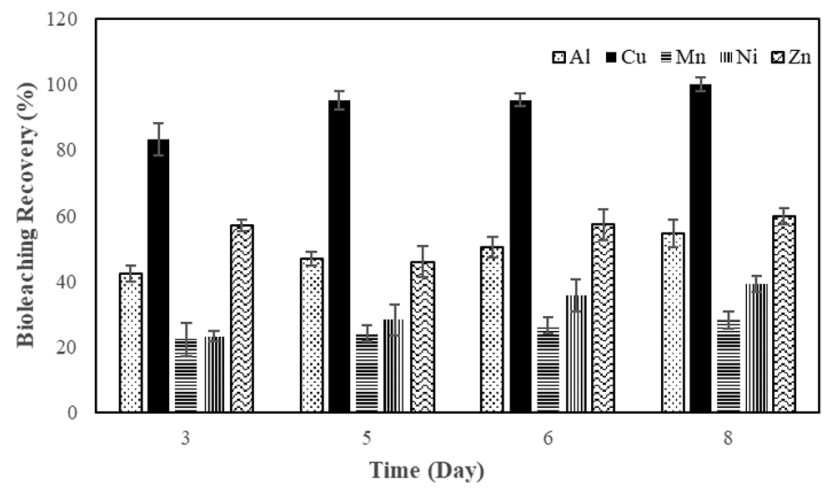

Fig. 3 Metal recoveries for $1.0 \% w / v$ pulp density

that the initial ORP increase observed after e-waste addition could be due to the destruction of metal oxides available in e-waste, which increase the amount of dissolved oxygen in the medium [40].

As illustrated in Fig. 3, the metal recovery by bioleaching for the flasks with $1.00 \% \mathrm{w} / \mathrm{v} \mathrm{PCBs}$, in addition to copper, leaches other base metals from the PCBs, by redoxolysis and acidolysis mechanisms. Redoxolysis refers to electron exchange reaction between elemental metals and the ferric-ferrous redox couple. Only metals that have a standard potential with higher negative value than that of the ferricferrous redox couple in a standard oxidation-potential table can go through this reaction. As an example, aluminium can be dissolved through electron exchange with ferric ions. However, aluminium is typically coated with a thin layer of protective oxide. The oxide can be dissolved by acidolysis (proton attack: $\mathrm{Al}_{2} \mathrm{O}_{3}+6 \mathrm{H}^{+} \rightarrow 2 \mathrm{Al}^{3+}+3 \mathrm{H}_{2} \mathrm{O}$ [43]), so that the exposed aluminium can undergo electron exchange with ferric ions (redoxolysis). As such, the bioleaching reaction continued for 8 days, when $100 \%$ copper recovery with bioleaching was achieved. In addition to copper, the bioleachate contains other metals including iron and magnesium, which have been either fed into the medium or bioleached from PCBs (Table 3). This resulting mixture in the bioleachate entails a challenging selective copper recovery from the bioleachate, which could be heterogeneous due to presence of several other base metals and components that might interfere with plating of copper.

\section{Electrowinning Results}

The bioleachate obtained from the highest pulp density, the composition of which was determined by ICP analysis and is described in Table 3, was used for electrowinning. Standard reduction potentials are also given for the metals present in the bioleachate. For cupric ions the reduction half reaction is:

$\mathrm{Cu}^{2+}+2 \mathrm{e}^{-} \rightarrow \mathrm{Cu}^{0}$

The standard reduction potential, $\mathrm{E}^{\circ}$, is $+0.34 \mathrm{~V}$ and the Gibbs free energy, $\Delta \mathrm{G},-66 \mathrm{~kJ}$. Nickel, iron, zinc and 
Table 3 Bioleachate metal composition and standard potentials of metals

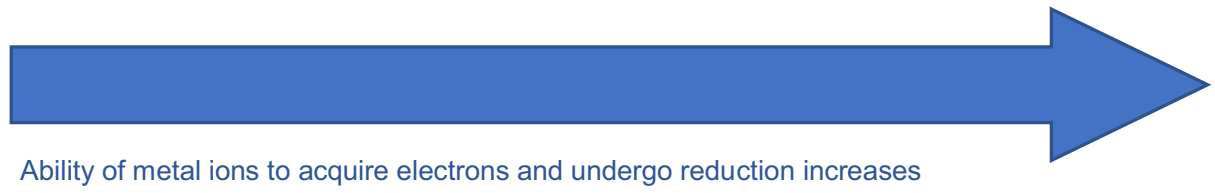

\begin{tabular}{lllllllll}
\hline Metal & $\mathrm{Na}$ & $\mathrm{Mg}$ & $\mathrm{Al}$ & $\mathrm{Mn}$ & $\mathrm{Zn}$ & $\mathrm{Fe}$ & $\mathrm{Ni}$ \\
\hline Concentration $(\mathrm{mg} / \mathrm{l})$ & 17 & 56 & 180 & 6 & 19 & 400 & 17 \\
Standard potential (V) & -2.71 & -2.37 & -1.6 & -1.19 & -0.76 & -0.45 & -0.26 & +0.34 \\
\hline
\end{tabular}

manganese ions may also be reduced to their base metal, but their standard reduction potentials have negative values, see Table 3, and all half reactions therefore have a positive $\Delta \mathrm{G}$. The reduction of these metals is less likely, and so the cupric ions ability to readily accept electrons and undergo reduction make it the more likely species to be reduced to its base metal. For sodium, magnesium, and aluminum, there is no possibility of metallic ion reduction at the cathode, the decomposition of water into hydrogen will be the more favorable reaction [44].

The reaction at the mixed metal oxide anode [45] is the oxidation of water into oxygen (Eq. 5), although the possibility of oxidizing ferrous back to ferric cannot be excluded, in which case any ferric generated can be recycled to the bioleaching unit to accelerate the metal dissolution process.

$2 \mathrm{H}_{2} \mathrm{O} \rightarrow \mathrm{O}_{2}+4 \mathrm{H}^{+}+4 \mathrm{e}^{-}$

Electrowinning was performed first on a mimic solution containing metallic ions as expressed in Table 3 for $5 \mathrm{~h}$. The cell voltage, on average, was equal to $2 \mathrm{~V}$ during the electrowinning process. Every hour the cathode was taken out and weighed to calculate the amount of copper deposited on the cathode. The theoretical mass of copper plated was calculated from the charge passed according to Faraday's laws summarized as:

$\mathrm{w}=\frac{\mathrm{itM}}{\mathrm{zF}}$

in which $w$ is the mass of copper plated, $i$ is the set current (A), $t$ is electrowinning time (s), $M$ is the metal molecular weight, $z$ is the number of electrons ( 2 in this case) and $F$ is the Faraday constant $\left(96,485 \mathrm{C} \mathrm{mol}^{-1}\right)$.

The mass gain of the cathode versus electrowinning time for the mimic solution containing all metals, is shown in Fig. 4a. It can be seen that as the electrowinning time increases the mass of copper deposited on the cathode falls below the theoretical value expected. After the first hour of the test, the actual rate of deposition is close to the
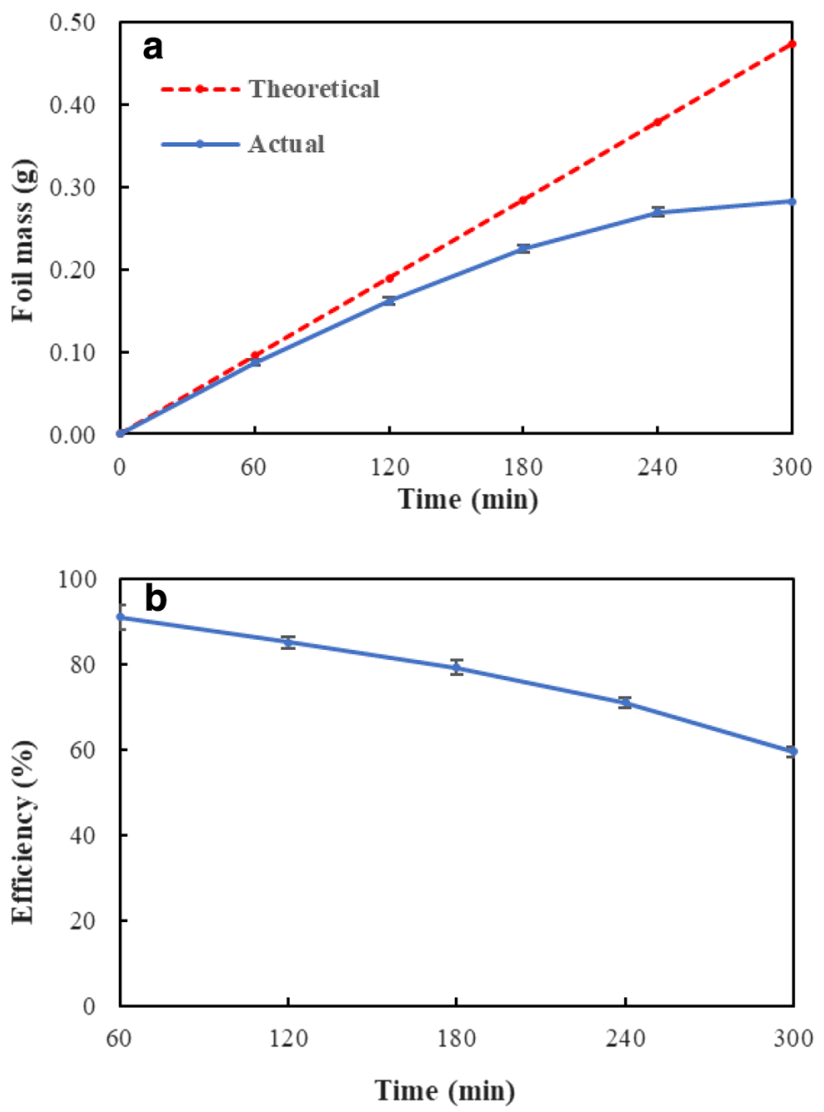

Fig. 4 a Mass of copper collected at cathode versus time b current efficiency versus time

calculated theoretical rate, $0.09 \mathrm{~g} / \mathrm{h}$. During the last hour of the experiment, the observed rate dropped to $0.01 \mathrm{~g} / \mathrm{h}$. A plot of the current efficiency versus time (Fig. 4b) also confirms this observation. The current efficiency drops from 91 to $59 \%$ after $5 \mathrm{~h}$. It can be explained by the overall decrease in cupric ion concentration in the leachate. At low concentrations, the mass transport of ions to the electrode surface becomes the limiting factor, and other electrochemical reactions, other than copper deposition, 


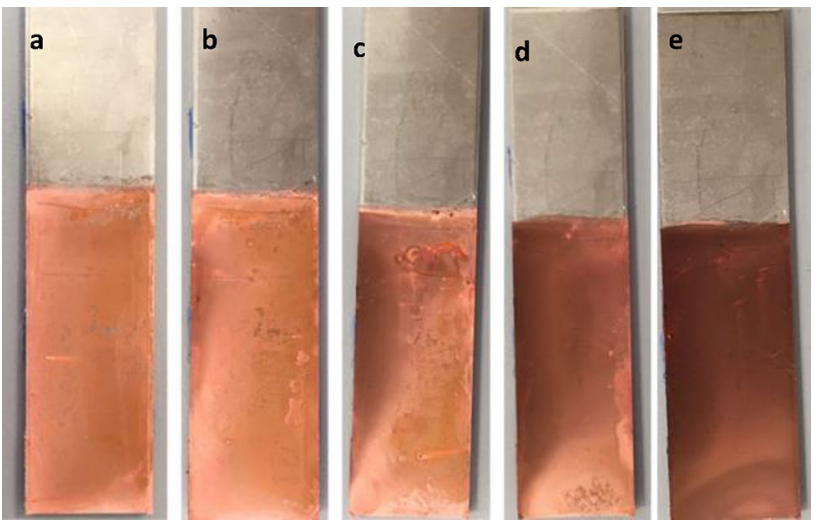

Fig. 5 Foil appearance versus time from mimic solution with all metals (according to Table 2) after a $1 \mathrm{~h}, \mathbf{b} 2 \mathrm{~h}, \mathbf{c} 3 \mathrm{~h}, \mathbf{d} 4 \mathrm{~h}$ e $5 \mathrm{~h}$

can occur [46]. Figure 5 illustrates the accumulation of the copper deposit over time. As the electrowinning process progresses, it can be seen that the deposit darkens and becomes rougher. This is also clear evidence that another electrochemical reaction such as hydrogen evolution is taking place at the copper cathode in the latter stages of the experiment [47].

Based on the above results, a time of $3 \mathrm{~h}$ was selected as the total plating time for future electrowinning tests from (1) a mimic solution containing all metals present in $9 \mathrm{k}$ medium, (2) the bioleachate obtained from $1.00 \% \mathrm{w} / \mathrm{v}$ PCBs. Each test was performed in 3 replicates. Successful copper plating was obtained from the two solutions at good recovery $(75 \%+)$ and current efficiency values $(80 \%+)$, see Table 4 , at a current density of $10 \mathrm{~mA} / \mathrm{cm}^{2}$. To maintain these high values, the electrowinning process should run as a 'feed and bleed' system in order to maintain the copper concentration $\geq 2 \mathrm{~g} / \mathrm{l}$. The 'bleed' from the electroplating unit, depleted of cupric ions, can be returned back to the bioleaching unit where the ferrous ions can be converted back to ferric ions for continued dissolution of base metals from the PCB pulp. The accumulation of other metal ions in the leachate can continue until their concentration is suitable for processing by electrowinning or an ion-exchange recovery unit.

Table 4 Electrowinning recovery and current efficiency of mimic solution and bioleachate

\begin{tabular}{lll}
\hline Solution & Recovery (\%) & Efficiency (\%) \\
\hline $\begin{array}{l}\text { Mimic solution containing } \\
\text { all metals in 9 k medium }\end{array}$ & 85.3 & 87.0 \\
$\begin{array}{l}\text { Bioleachate obtained from } \\
1.00 \% w / v \text { PCBs }\end{array}$ & 75.8 & 80.6 \\
\hline
\end{tabular}

\section{Analysis of the Copper Product}

Following the electrowinning tests, the copper foil produced was manually peeled away from the stainless steel cathode / substrate. The morphology and purity of the copper deposit were analysed using the SEM-EDX system and ICP-OES as described in Sect. 2.4. Figure 6a shows a micrograph of the copper foil obtained from the mimic $9 \mathrm{~K}$ medium / metal ion solution. A nodular, compact deposit was observed at the plating current density of $10 \mathrm{~mA} / \mathrm{cm}^{2}$. Analysis of the foil by EDX showed a high purity copper deposit (99.6\%), as seen in Fig. 6b. The carbon present in the spectrum is an artificial peak from hydrocarbon contamination, which often induces a background carbon signal, and can be ignored. A small amount of oxygen is also present that can be attributed to the reaction of the copper surface with atmospheric oxygen. The reduction of other aqueous metal ions, see Table 3 , are clearly not favorable at the electrode surface. Once plated with copper, the stainless steel substrate effectively becomes a copper electrode. Copper is a good electrocatalyst for hydrogen evolution, and as such, the reduction of protons to hydrogen gas is the favoured reaction when the mass transport of cupric ions is the limiting factor. Furthermore, the presence of the $9 \mathrm{~K}$ medium does not interfere with copper deposition and foil formation on the stainless steel cathode is still possible.

Figure 7a shows a photograph of the foil as the result of electrowinning from a bioleachate at $1.00 \% \mathrm{w} / v$ pulp density.
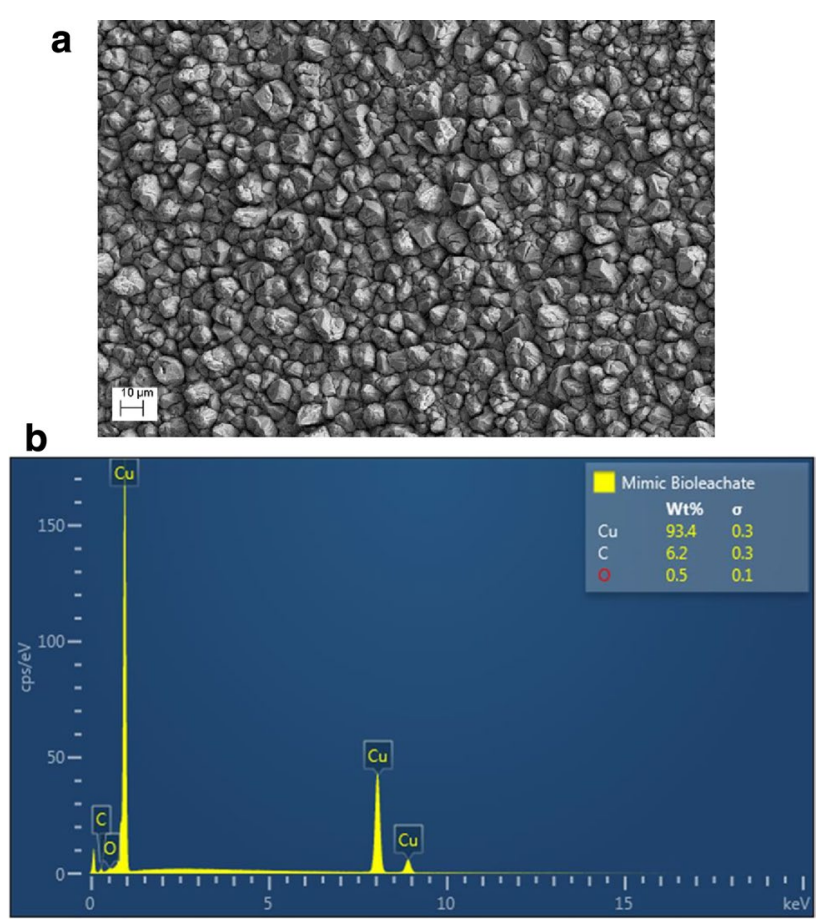

Fig. 6 Analysis of copper foil obtained from mimic solution containing metals in $9 \mathrm{~K}$ medium a SEM b EDX 
a

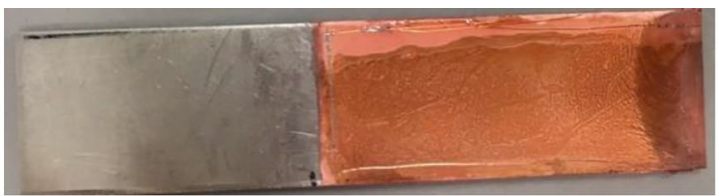

b

c
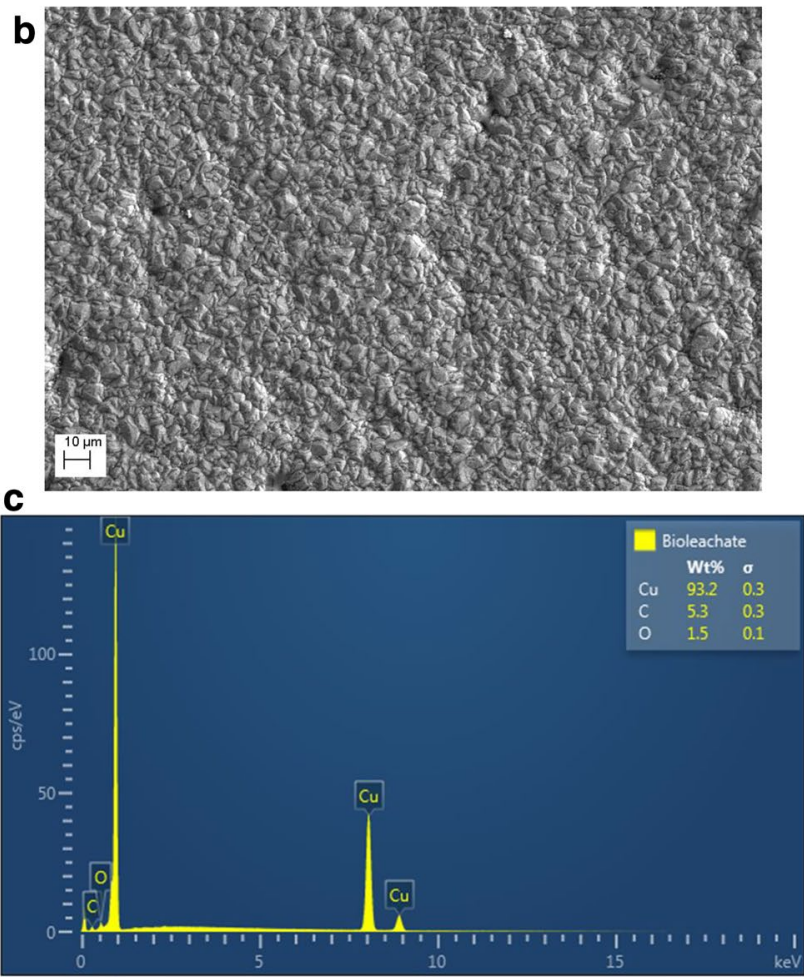

Fig. 7 a Final product from bioleachate as a foil b foil morphology with SEM c EDX analysis of foil

The SEM micrograph (Fig. 7b) of the copper foil exemplifies a typical copper electroplated surface [48, 49], and a purity of deposit of $98.5 \%$ was measured by EDX (Fig. 7c). Again the carbon peak from contamination can be ignored and the EDX result was confirmed by ICP-OES analysis, which determined $99.55 \mathrm{wt} \%$ copper, $0.25 \mathrm{wt} \%$ sulphur and $0.2 \mathrm{wt} \%$ potassium. Previously, very high purity copper (99.83\%) was obtained by combining solvent extraction and electrowinning processes [31]. Obtaining very high purity copper without using solvent extraction, as achieved in this study, has several environmental and economic benefits. Another study, that extracted copper with cementation with zinc, after separation of iron with precipitation, obtained copper precipitate with $95 \%$ purity, but not in the form of foil [9]. Moreover, an electrowinning process is scalable and foil can be recovered in a continuous process using a rotating drum electrode [50].

The high purity $(+99 \%)$ copper product obtained here from bioleachate using a single electrowinning process demonstrates that there is no need for solvent extraction. The high purity foil indicates that the electrowinning has been performed selectively. This selective extraction of copper, without solvent extraction, reduces the operational costs and eliminates the requirement for a toxic, low flash point solvent. This novel approach of copper separation from WEEE also provides an example of a pre-treatment method, which would facilitate the subsequent recovery of other precious metal [51].

\section{Mass Balance and Possibility of Reuse of Iron}

In this work $75.8 \%$ of the copper available in the PCBs has been recovered as copper foil using bioleaching and electrowinning techniques. The mass balance of iron, highlights that the large amounts of iron salt that is fed to the $9 \mathrm{k}$ medium, precipitates in form of jarosite. By preventing and reducing the jarosite formation, iron would be present in the ferrous form in the remaining solution after electrowinning, with the possibility to be recycled for further bioleaching activity of the bacteria. However, in this work only $4.4 \mathrm{wt} \%$ of iron remained in the solution after electrowinning. To prevent this loss in future experiments the following options are suggested:

1. The addition of sulphur to the medium; as the bacteria is both sulphur and iron oxidiser, it is expected that sulphur would be converted to sulphuric acid, therefore lowering the $\mathrm{pH}$ of medium and reducing jarosite formation.

2. The use of different growth medium; the acidophilic basal salts and trace element mixture is a promising medium that has been suggested by other researchers, which contains lower amounts of ferrous sulphate and therefore is expected to result in less jarosite formation [52].

\section{Recommendation and Future Research}

By changing the process to continuous mode, several advantages can be obtained in the future of this research. Working in continuous mode, would provide the possibility of accumulation of metals in the bioleachate, and consequently in the electrowinning tank. This would help the plating of other base metals such as zinc and nickel, when their concentration becomes significant. Using a feed and bleed system, the concentration of copper in the electrowinning process would be maintained at a level where the formation of a copper foil, with optimum physical properties, would be maintained. After large scale application, a thorough techno-economic assessment is necessary for evaluating the feasibility of the process.

Applying Life Cycle Assessment, would be very helpful for quantifying the environmental impact of the process as it has been performed in previous research studies [9, 53]. As mentioned earlier, the iron species remains in the 
leachate in the ferrous form and can potentially be reused for the next batches of bioleaching, as targeted in future work.

The results obtained in this work provide pure copper foil as a value-added product for return to the market from discarded IT networking and telecommunication equipment.

\section{Conclusion}

In this study, the closed-loop process of copper recovery from PCBs was investigated. By combining bioleaching and electrowinning, a model of closed-loop recycling of metals from PCBs was demonstrated, which selectively extracted and recovered copper. This includes the solubilisation of copper from PCBs using an environmentally friendly method of bioleaching, and copper foil production through electrowinning. In this single batch method, $75.8 \%$ of copper available in PCB was recovered as pure copper foil, suitable for multiple applications including the manufacturing of PCBs. In the present study, the use of the $9 \mathrm{k}$ medium requires a large fraction of ferrous sulphate for bacterial growth, which resulted in the excessive byproduct formation in the form of jarosite. It is expected that the careful reduction of jarosite formation, which could be achieved by modifying the growth medium, would provide a source or iron for the next bioleaching batches, while reducing potential contamination in electrowinning. In addition, this approach of selective copper separation from WEEE provides a pretreatment method, which can facilitate and promote the subsequent recovery of other precious metals, which otherwise might be hindered by the presence of copper. Bioleaching has been demonstrated for the solubilisation of a large number of metals, and it is expected that selective electrowinning from leachate can be defined for other metals. Therefore, this model should be targeted as a general method of closedloop recycling for metals from WEEE and other solid wastes containing metals, to support a circular economy with high value for several industrial applications.

Acknowledgment The authors would like to thank Prof. David Barrie Johnson for providing the A. ferrooxidans bacteria; and Innovate UK and Network 2 Supplies Limited for funding. We would additionally like to thank Network 2 Supplies Limited for providing the waste PCBs used throughout this study.

\section{Compliance with Ethical Standards}

Competing interest The authors declare the following financial interests/personal relationships, which may be considered as potential competing interests: this work is part of an Innovate UK funded Knowledge Transfer Partnership between Coventry University and Network 2 Supplies Limited.
Open Access This article is licensed under a Creative Commons Attribution 4.0 International License, which permits use, sharing, adaptation, distribution and reproduction in any medium or format, as long as you give appropriate credit to the original author(s) and the source, provide a link to the Creative Commons licence, and indicate if changes were made. The images or other third party material in this article are included in the article's Creative Commons licence, unless indicated otherwise in a credit line to the material. If material is not included in the article's Creative Commons licence and your intended use is not permitted by statutory regulation or exceeds the permitted use, you will need to obtain permission directly from the copyright holder. To view a copy of this licence, visit http://creativecommons.org/licenses/by/4.0/.

\section{References}

1. Lee, E.Y., Seul S. Y.: Copper and It Electrifying Future. DBS Asian Insight, pp. 14-15 (2018)

2. Norgate, T., Haque, N.: Energy and greenhouse gas impacts of mining and mineral processing operations. J. Clean. Prod. 18, 266-274 (2010)

3. Charles, R.G., Douglas, P., Hallin, I.L., Matthews, I., Liversage, G.: An investigation of trends in precious metal and copper content of RAM modules in WEEE: implications for long term recycling potential. Waste Manag. 60, 505-520 (2017)

4. Nowakowski, P.: A proposal to improve e-waste collection efficiency in urban mining: container loading and vehicle routing problems - a case study of Poland. Waste Manag. 60, 494-504 (2017)

5. E-Scrap Recycling I DOWA ECO-SYSTEM Co., Ltd., https:// www.dowa-eco.co.jp/en/service/e-scrap-recycling. Accessed 5 May 2020

6. Boliden Rönnskär - Boliden, https://www.boliden.com/opera tions/smelters/boliden-ronnskar. Accessed 5 May 2020

7. Hazardous Waste Treatment I DOWA ECO-SYSTEM Co., Ltd., https://www.dowa-eco.co.jp/en/service/hazardous-waste-treat ment. Accessed 5 May 2020

8. Baniasadi, M., Vakilchap, F., Bahaloo-Horeh, N., Mousavi, S.M., Farnaud, S.: Advances in bioleaching as a sustainable method for metal recovery from e-waste: a review. J. Ind. Eng. Chem. 76, 75-90 (2019)

9. Amato, A., Becci, A., Beolchini, F.: Sustainable recovery of $\mathrm{Cu}, \mathrm{Fe}$ and $\mathrm{Zn}$ from end-of-life printed circuit boards. Resourc. Conserv. Recycl 158, 104792 (2020)

10. Xiang, Y., Wu, P., Zhu, N., Zhang, T., Liu, W., Wu, J., Li, P.: Bioleaching of copper from waste printed circuit boards by bacterial consortium enriched from acid mine drainage. J. Hazard. Mater. 184, 812-818 (2010)

11. Fathollahzadeh, H., Khaleque, H.N., Eksteen, J., Kaksonen, A.H., Watkin, E.L.J.: Effect of glycine on bioleaching of rare earth elements from Western Australian monazite by heterotrophic and autotrophic microorganisms. Hydrometallurgy 189, 105137 (2019)

12. Arshadi, M., Yaghmaei, S., Mousavi, S.M.: Content evaluation of different waste PCBs to enhance basic metals recycling. Resour. Conserv. Recycl. 139, 298-306 (2018)

13. Williams, P.T.: Valorization of printed circuit boards from waste electrical and electronic equipment by pyrolysis. Waste Biomass Valoriz. 1, 107-120 (2010)

14. Yildirir, E., Onwudili, J.A., Williams, P.T.: Chemical recycling of printed circuit board waste by depolymerization in sub- and supercritical solvents. Waste Biomass Valoriz. 6, 959-965 (2015)

15. Heydarian, A., Mousavi, S.M., Vakilchap, F., Baniasadi, M.: Application of a mixed culture of adapted acidophilic bacteria 
in two-step bioleaching of spent lithium-ion laptop batteries. J. Power Sources 378, 19-30 (2018)

16. Zeng, G., Luo, S., Deng, X., Li, L., Au, C.: Influence of silver ions on bioleaching of cobalt from spent lithium batteries. Miner. Eng. 49, 40-44 (2013)

17. Ijadi Bajestani, M., Mousavi, S.M., Shojaosadati, S.A.: Bioleaching of heavy metals from spent household batteries using Acidithiobacillus ferrooxidans: statistical evaluation and optimization. Sep. Purif. Technol. 132, 309-316 (2014)

18. Arshadi, M., Mousavi, S.M.: Simultaneous recovery of Ni and $\mathrm{Cu}$ from computer-printed circuit boards using bioleaching: statistical evaluation and optimization. Biores. Technol. 174, 233-242 (2014)

19. Mäkinen, J., Bachér, J., Kaartinen, T., Wahlström, M., Salminen, J.: The effect of flotation and parameters for bioleaching of printed circuit boards. Miner. Eng. 75, 26-31 (2015)

20. Pourhossein, F., Mousavi, S.M.: A novel step-wise indirect bioleaching using biogenic ferric agent for enhancement recovery of valuable metals from waste light emitting diode (WLED). J. Hazard. Mater. 378, 120648 (2019)

21. Pourhossein, F., Mousavi, S.M.: Enhancement of copper, nickel, and gallium recovery from LED waste by adaptation of Acidithiobacillus ferrooxidans. Waste Manage. 79, 98-108 (2018)

22. McKevitt, B., Dreisinger, D.: A comparison of various ion exchange resins for the removal of ferric ions from copper electrowinning electrolyte solutions Part II: electrolytes containing antimony and bismuth. Hydrometallurgy 98, 122-127 (2009)

23. Moats, M., Free, M.: A bright future for copper electrowinning. JOM. 59, 34-36 (2007)

24. Cooper, W.C.: Advances and future prospects in copper electrowinning. J. Appl. Electrochem. 15, 789-805 (1985)

25. Sodha, A.B., Tipre, D.R., Dave, S.R.: Optimisation of biohydrometallurgical batch reactor process for copper extraction and recovery from non-pulverized waste printed circuit boards. Hydrometallurgy 191, $105170(2020)$

26. Johnson, B.D., Hallberg, K.B.: Carbon, iron and sulfur metabolism in acidophilic micro-organisms. In: Poole, R.K. (ed.) Advances in microbial physiology, pp. 201-255. Elsevier, New York (2008)

27. Lister, T.E., Wang, P., Anderko, A.: Recovery of critical and value metals from mobile electronics enabled by electrochemical processing. Hydrometallurgy 149, 228-237 (2014)

28. Pilone, D., Kelsall, G.H.: Metal recovery from electronic scrap by leaching and electrowinning IV. In: Young, C., Alfantazi, A., Anderson, C., James, A., Dreisinger, D., Harris, B. (eds.) Electrometallurgy and environmental hydrometallurgy, pp. 1565-1575. Wiley, Hoboken, NJ (2013)

29. Vegliò, F., Quaresima, R., Fornari, P., Ubaldini, S.: Recovery of valuable metals from electronic and galvanic industrial wastes by leaching and electrowinning. Waste Manag. 23, 245-252 (2003)

30. Willner, J., Fornalczyk, A., Saternus, M.: Selective recovery of copper from solutions after bioleaching electronic waste. Nova Biotechnol. Chim. 14, 32-37 (2015)

31. Zhang, C., Wang, J., Bai, J., Mao, W.: Production of High Purity Copper from Bio-Leaching Solutions of Waste Printed Circuit Boards. In: 2010 4th International Conference on Bioinformatics and Biomedical Engineering. IEEE, Chengdu, China, pp. 1-4 (2010)

32. Arshadi, M., Mousavi, S.M.: Enhancement of simultaneous gold and copper extraction from computer printed circuit boards using Bacillus megaterium. Biores. Technol. 175, 315-324 (2015)

33. Li, J., Lu, J., Lu, X., Tu, B., Ouyang, B., Han, X., Wang, R.: Sulfur transformation in microbially mediated pyrite oxidation by Acidithiobacillus ferrooxidans : insights from $\mathrm{x}$-ray photoelectron spectroscopy-based quantitative depth profiling. Geomicrobiol J. 33, 118-134 (2016)
34. Karamanev, D.G., Nikolov, L.N., Mamatarkova, V.: Rapid simultaneous quantitative determination of ferric and ferrous ions in drainage waters and similar solutions. Miner. Eng. 15, 341-346 (2002)

35. de Paula, W.J., Tavares, P.L., de Pereira, D.C., Tavares, G.M., Silva, F.L., Almeida, P.S., Braga, H.A.C.: A review on gallium nitride switching power devices and applications. In: 2017 Brazilian Power Electronics Conference (COBEP). IEEE, Juiz de For a, pp. 1-7 (2017)

36. Pawinanto, R.E., Yunas, J., Said, M.M., Noor, M.M., Majlis, B.Y.: Design and fabrication of PCB based planar micro-coil for magnetic MEMS actuator. In: 2014 IEEE international conference on semiconductor electronics (ICSE2014). IEEE, Kuala Lumpur, Malaysia, pp. 487-490 (2014)

37. Valix, M.: Bioleaching of electronic waste: milestones and challenges. In: Larroche, C., Sanroman, M., Du, G., Pandey, A. (eds.) Current Developments in Biotechnology and Bioengineering, pp. 421-422. Elsevier, Amsterdam (2017)

38. Falagán, C., Johnson, D.B.: The significance of $\mathrm{pH}$ in dictating the relative toxicities of chloride and copper to acidophilic bacteria. Res. Microbiol. 169, 552-557 (2018)

39. Quatrini, R., Appia-Ayme, C., Denis, Y., Jedlicki, E., Holmes, D.S., Bonnefoy, V.: Extending the models for iron and sulfur oxidation in the extreme Acidophile Acidithiobacillus ferrooxidans. BMC Genomics. 10, 394 (2009)

40. Sadeghabad, M.S., Bahaloo-Horeh, N., Mousavi, S.M.: Using bacterial culture supernatant for extraction of manganese and zinc from waste alkaline button-cell batteries. Hydrometallurgy 188, 81-91 (2019)

41. Fonti, V., Dell'Anno, A., Beolchini, F.: Does bioleaching represent a biotechnological strategy for remediation of contaminated sediments? Sci. Total Environ. 563-564, 302-319 (2016)

42. Nazari, B., Jorjani, E., Hani, H., Manafi, Z., Riahi, A.: Formation of jarosite and its effect on important ions for Acidithiobacillus ferrooxidans bacteria. Trans. Nonferrous Metals Soc. China. 24, 1152-1160 (2014)

43. Seidel, A., Zimmels, Y.: Mechanism and kinetics of aluminum and iron leaching from coal fly ash by sulfuric acid. Chem. Eng. Sci. 53, 3835-3852 (1998)

44. Sillanpää, M., Shestakova, M.: Electrochemical water treatment methods. In: Martínez-Huitle, C.A., Rodrigo, M.A., Scialdone, O. (eds.) Electrochemical Water Treatment Methods, pp. 47-130. Elsevier, New York (2017)

45. Cobley, A.J., Gabe, D.R., Graves, J.E.: The use of insoluble anodes in acid sulphate copper electrodeposition solutions. Trans. IMF. 79, 112-118 (2001)

46. Pletcher, D., Walsh, F.C.: Industrial Electrochemistry. Springer, Dordrecht (1993)

47. Schlesinger, M., Paunovic, M.: Modern Electroplating (The ECS Series of Texts and Monographs). Wiley, Hoboken, NJ (2010)

48. Haba, T., Ikeda, K., Uosaki, K.: Electrochemical and in situ SERS study of the role of an inhibiting additive in selective electrodeposition of copper in sulfuric acid. Electrochem. Commun. 98, 19-22 (2019)

49. Dow, W.-P., Huang, H.-S.: Roles of chloride ion in microvia filling by copper electrodeposition. J. Electrochem. Soc. 152, C67-C76 (2005)

50. Copper Foil Manufacturing.: Total Materia Article, https $: / /$ www.total materia.com/page.aspx ?ID=Check Artic le $\&$ site $=\mathrm{ktn} \& \mathrm{NM}=352$. Accessed 6 May 2020

51. Iş1ldar, A., van de Vossenberg, J., Rene, E.R., van Hullebusch, E.D., Lens, P.N.L.: Two-step bioleaching of copper and gold from discarded printed circuit boards (PCB). Waste Manag. 57, 149-157 (2016) 
52. Wakeman, K., Auvinen, H., Johnson, D.B.: Microbiological and geochemical dynamics in simulated-heap leaching of a polymetallic sulfide ore. Biotechnol. Bioeng. 101, 739-750 (2008)

53. Becci, A., Amato, A., Fonti, V., Karaj, D., Beolchini, F.: An innovative biotechnology for metal recovery from printed circuit boards. Resourc. Conserv. Recycl. 153, 104549 (2020)
Publisher's Note Springer Nature remains neutral with regard to jurisdictional claims in published maps and institutional affiliations.

\section{Affiliations}

\section{Mahsa Baniasadi ${ }^{1,2,5} \cdot$ John E. Graves ${ }^{1,3} \cdot$ Daniel A. Ray $^{1,2,5} \cdot$ Angélique Lindamulage De Silva ${ }^{4} \cdot$ Derek Renshaw $^{1,2}$. Sebastien Farnaud ${ }^{1,2}$ (iD}

1 Bioleaching Group, Coventry University, Priory Street, Coventry CV1 5FB, UK

2 Centre of Sport, Exercise and Life Sciences, Faculty of Health and Life Sciences, Coventry University, Priory Street, Coventry CV1 5FB, UK

3 Functional Materials Group, IFTC, Faculty of Engineering, Environment and Computing, Coventry University, Priory Street, Coventry CV1 5FB, UK
4 École Nationale Supérieure de Chimie de Rennes, 11 allée de Beaulieu - CS 50837, 35708 Rennes Cedex 7, France

5 Network 2 Supplies (N2S) Ltd, Network House, Western Way, Bury St Edmunds, Bury Saint Edmunds IP33 3SP, UK 